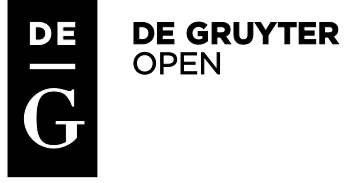

\title{
INTEGRATING SOFT SKILLS IN HIGHER EDUCATION AND THE EFL CLASSROOM: KNOWLEDGE BEYOND LANGUAGE LEARNING
}

\section{Elena Spirovska Tevdovska}

South East European University, Language Center

E-mail: E.Spirovska@Seeu.Edu.Mk

\section{DOI: 10.1515/seeur-2015-0031}

\begin{abstract}
The purpose of this article is to discuss the importance of soft skills in the context of higher education and in the context of the foreign language learning classroom. The article aims to define the notion of soft skills and to offer possible ways of grouping soft skills. It also provides ways of including soft skills instruction in the context of higher education. In addition, the article aims to propose models of implementing soft skills in foreign language learning and teaching situations and to suggest teaching procedures and activities which will facilitate the introduction of soft skills in the EFL (English as a foreign language) classroom at South East European University. The article also aims to discuss the need of including soft skills in undergraduate studies curricula and to provide arguments in favour of including soft skills. The article will also present participants' views and perceptions, collected via survey, of the importance and necessity of soft skills for their future careers and workplaces. The conclusion will offer some practical suggestions regarding soft skill inclusion in the EFL classroom.
\end{abstract}

Key words: soft skills, hard skills, EFL classroom, model, activities. 


\section{DEFINITION OF SOFT SKILLS VS HARD SKILLS IN THE CONTEXT OF HIGHER EDUCATION}

This paper aims to define the notion of soft skills, to analyze the necessity of introducing soft skills in a higher educational context with an emphasis on foreign language learning and teaching situations, and to suggest methods and ways of introducing soft skills in the language learning classroom. This study attempted to answer the following research questions:

- How can we define the term soft skills?

- How can we group soft skills?

- Are soft skills important in the context of workplace and career development?

- Can soft skills be taught?

- Can they be incorporated in the context of English language teaching and learning?

There is a need to define the term soft skills in the context of higher education and to distinguish this term from the content area knowledge and expertise which can be defined as hard skills/ knowledge.

What are soft skills? Robles (2012) provides the following definition: "Soft skills are character traits, attitudes and behaviours-rather than technical aptitude or knowledge. Soft skills are the intangible, non-technical, personality-specific skills that determine one's strengths as a leader, facilitator, mediator, and negotiator” (Robles, 2012, p.457).

The process of defining and determining the scope of soft skills is not straightforward. The fact that various authors list different skills and group them in a various manners adds to the complexity of this question. For instance, Nieragden (2000) lists four groups of soft skills:

- Interaction: (such as attitude awareness, conflict handling, tolerance)

- Self-Management: (such as decision making, willingness to learn, self-discipline and resistance to stress)

- Communication: (such as listening skills, presentation skills)

- Organization: (problem solving)

On the other hand, according to Shakir (2009, pp. 310-311) the following skills can be defined as soft skills:

- Communication skills: (expressing thoughts and arguments with clarity) 
- Critical thinking and problem solving: (ability to analyze, evaluate and apply knowledge)

- Ability to cooperate with others: (ability to work in a team and cooperate with individuals coming from various backgrounds in terms of society, education and culture, as well as being able to achieve the same goals).

- Lifelong learning and information management skills: (ability/skill to learn and search and process relevant information)

- Ethics and professional moral: (ability to apply moral standards in context of professional practice)

- Leadership skills: (ability to lead and understand the leadership roles)

Gallivan, Truex and Kvasny (2008, in T. Chamorro-Premuzic et al. 2010) describe communication, leadership, organization, self-motivation and creativity as important soft skills.

Sometimes, a skill can be considered as important in one context but essential in another. In order to illustrate this point, Schulz (2008, p. 147) gives the following example:

A subject may be considered as a soft skill in one particular area and may be considered as a hard skill in another. On top of it, the understanding of what should be recognized as a soft skill varies widely. Knowledge in project management for instance is nice to have for an electrical engineer, but it is a "must to have" for a civil engineer. Training in cultural awareness might be useful for chemist, but it is an absolute necessity for public or human resource management in societies of diverse cultures.

Schulz $(2008, p .147)$

Regardless of the difficulty of defining the notion and the scope of soft skills, the importance of providing soft skills in the context of higher education can be perceived clearly. It can be perceived that skills such as communication skills, critical thinking and interpersonal skills which include listening, problem solving and cultural awareness (Neally, 2005) are also necessary.

\section{THE IMPORTANCE OF SOFT SKILLS IN HIGHER EDUCATION}

There is a complaint that university graduates, regardless of their level of expertise, very often lack basic communication and soft skills and, as a result, they are not ready for employment. According to Chamorro-Premuzic, 
Arteche, Bremner, Greven and Furnham (2010, p.221) it is important to implement " ...a set of non-academic attributes, such as the ability to cooperate, communicate and solve problems, often referred to as generic or soft skills in higher education". They also state the following: "Unlike academic or disciplinary knowledge, which is subject-based, content specific and formally assessed, soft skills comprise a range of competencies that are independent of, albeit often developed by, formal curricula and rarely assessed explicitly" (Chamorro-Premuzic et al., 2010, p.221). The quote above illustrates the situation in higher education today: the reality is that although perceived as essential and important, soft skills are rarely included in the course curricula and in the assessment criteria. In addition, the majority of soft skills cannot be assessed with summative assessment methods and depend on subjective evaluation.

On the other hand, the employers believe that soft skills are important and necessary attributes of their future employees or applicants. They believe that the importance of soft skills almost equals the importance of hard skills. For instance, in his research, Robles (2012) lists 10 soft skills which are perceived as necessary in workplaces. The perceptions of executives include soft skills such as communication, courtesy, flexibility, integrity, interpersonal skills, positive attitude, professionalism, responsibility, teamwork and work ethics. According to the results of his research, the most needed soft skills, as perceived by employers, are integrity, communication and interpersonal skills, which were identified as important or extremely important. Robles (2012, p.461) states the following: "Over a decade ago, the National Business Education Association's Policies Commission for Business and Economic Education (2000) noted the upcoming shortage of skills in today's workplace that stresses the need for interpersonal skills, above and beyond the academics, technical skills, and hands-on training”. Therefore, it can be concluded that integration of soft skills increases students' chance of employment and presents them with better prospects in terms of their future successful carriers.

After analyzing the cultural and societal setting of the University, this necessity of introducing soft skills in learning and teaching is obvious. South East European University is located in the Republic of Macedonia, a relatively small country where multiple nations, religions as well as languages co-exist. The structure of the students enrolled reflects this reality: although the majority of the students are Albanians, there are Macedonian as well as Turkish students and Roma students. Most of the students are Muslims, in addition to Orthodox Christians as well as students with different religious backgrounds. Most of the students are coming from Macedonia and neighbouring countries, notably Kosovo, or Southern Serbia. In addition, SEEU is hosting a group of Turkish students. They study at 5 different 
faculties including The Faculty of Business and Economics; the Faculty of Contemporary Sciences and Technologies; The Faculty of Languages, Cultures and Communications; the Faculty of Law; and the Faculty of Public Administration and Political Sciences.

The mixture of different ethnicities, religions and educational backgrounds, requires that the students be able to communicate and understand effectively, and to be able to understand and embrace differences and similarities. This multicultural environment is mirrored by companies which will potentially employ the students. It can be concluded that students need soft skills in order to be able to communicate effectively during their studies and in their future work place and careers. The report after a meeting between SEEU representatives and stakeholders and company representatives, held on March 12, 2015, lists the soft skills which are perceived as necessary, according to the company representatives' input. The list includes among other skills, being able to sustain open and positive relations with colleagues (interpersonal skills), behaviour adaptability, communication and teamwork, as well as an ability for self-learning and ethical knowledge. Therefore, we can conclude that it is important that soft skills should be included in the Faculty curricula, as a part of the core or elective courses.

\section{PARTICIPANTS' PERCEPTIONS OF THE NECESSITY OF SOFT SKILLS, SURVEY RESULTS AND CONCLUSIONS}

Among the objectives of this article, apart from defining the notion of soft skills, presenting a brief summary of the relevant literature and suggesting models of implementation of soft skills in the ELT context, is to examine the perceptions of the importance of soft skills and the necessity of developing soft skills of the former students who studied at South East European University.

For this purpose, a questionnaire was developed. The questionnaire targeted the former students who studied at South East European University and who, after the completion of their studies, proceeded with their master studies or doctoral studies either at SEEU or at other universities, including universities abroad. These participants were accessed via social networks and the link of the questionnaire was sent to them. The majority of the participants who took the survey study (MA or PhD studies) and work at the same time. Out of 23 respondents who took the questionnaire, 20 are employed in various 
companies (software developing companies, banks) or teach in private or public schools.

The assumption was that after the completion of their undergraduate studies, most of these young people would be in situations in which they would need their knowledge from their respective areas of expertise (hard skills), as well as their language knowledge and above all, their soft skills in order to be able to establish proper conduct and rapport at their workplace. Therefore, it was expected that the participants who took the survey were in a situation to use their soft skills or to be aware of the lack of them in their manner of behaviour.

In total, 23 participants took the questionnaire. Out of 23 former students, 14 students graduated from the Faculty of Languages, Cultures and Communications; 4 from the Faculty of Contemporary Sciences and Technologies; 2 from the Faculty of Business and Economics; 2 from the Faculty of Law; and 1 from the Faculty of Public Administration and Political Sciences. Their age varied from 24-28 years old.

The results of the survey indicated that the majority of the participants believed that they were sometimes prepared to communicate properly with their colleagues. Only 3 of them believed that they are very often able to communicate in an appropriate way with their colleagues. The majority of them perceive the relationship between supervisors and subordinates in our society as appropriate only in rare cases. The majority of them believe that the relationship with their colleagues can be improved, although they have indicated that they have worked successfully as a member of a team in the past (15 of them), and often had an opportunity to use their colleagues' help in the past often or sometimes (19 in total). The majority of them (17) often or sometimes had to deal with criticism at their educational environment or their workplace. The majority of them (18) were aware that they are not dealing with criticism successfully. A significant number of affirmative responses indicated that the participants were often or sometimes in a situation to deal with irritated clients. On the other hand, only 6 of them had an impression that they could manage this type of situation frequently and successfully. In addition, from the responses, it could be concluded that a significant number of respondents had to communicate to their supervisor that they disagree or they are dissatisfied or often had to deal with disagreement or tense situations between themselves and colleagues or clients. Some of the participants were in situations to perceive unethical behaviour by their colleagues or to be asked to do something unethical. 
In terms of language, the majority of them had to use their language skills and knowledge when they had to communicate via e-mails, present or listen to presentations. Furthermore, a significant number of the participants had to solve problems or present innovative ideas in order to do so. More than half of the students could perceive unethical behaviour by their colleagues, and 16 were asked to do something which they perceived as unethical at their workplace. Finally, when asked if their undergraduate studies could have prepared them to understand and deal better with these situations, most of them replied affirmatively and the majority (20) stated that the skills of understanding and communicating with others can be learned.

As a result of the survey, several conclusions could be drawn. First, it can be concluded that the majority of the students, after completing their undergraduate studies, were in a position to use their soft skills or to be aware of the lack of the skills mentioned. The majority of them are aware that the connection between them, other colleagues or between the supervisors or the subordinates can and should be improved, since they perceived these connections as rarely appropriate. In addition, they were in a position to try to cope with criticism and to deal with unsatisfied clients, which, according to the answers, was not very successful.

It can be concluded that critical and innovative thinking was also needed, since a significant number of responses indicated that the respondents were expected to provide solutions or ideas. In workplace situations, the majority of the participants had to present or communicate in English.

Another significant conclusion is that several of the respondents could notice unethical situations or behaviours at work, which indicates that these types of situations exist and the students should be more aware of the potential ethical issues involved in their area of expertise.

In addition, it could be concluded that a significant number of respondents felt that during their undergraduate studies they should have been better prepared in terms of their ability to communicate properly and manage the situations which require not only their practical knowledge but also their soft skills.

\section{RECOMMENDATIONS}

One of the objectives of this article is to recommend ways which will facilitate the incorporation of soft skills in undergraduate curricula. Taking into consideration the educational and curriculum setting, three approaches in 
integrating soft skills in undergraduate curricula can be suggested. One way would be to create a separate university course which would include the development of soft skills as its primary objective. Although this appears to be the most logical approach, still, it can be the least practical one. A separate course would require the course and the programme to go through processes of accreditation, possibly changing the structure of the curriculum, which is frequently very difficult if not impossible. Another way would be to include soft skills training as an integral part of other courses. According to Robles (2010) soft skills can be included in undergraduate studies curricula. For the purpose of including soft skills, he suggests four steps of extending the content throughout the semester:

1. Introducing students to basic people skills and enabling them to communicate with others effectively;

2. Introducing essential customer/ client service skills;

3. Introducing problem solving tasks and discussions and reinforcing students' understanding of the previous two groups of skills;

4. Introducing activities such as role plays or dialogues in a mock business setting so that students can practice and demonstrate their understanding of soft skills.

However, this approach also presents difficulties. Taking into consideration the fact that the majority of academic curricula are burdened with significant content load, it would be logical to assume that adding soft skills training to certain courses could be too overwhelming and burdensome for the lecturers.

The most logical option, in that case, would be to include soft skills as an integral component of the language courses. Language courses are largely based on communication. In addition, a lot of teaching practices and materials include working on students' soft skills and ability to communicate effectively. The possible modes of introducing soft skills in the ELT context are discussed in the following section.

\section{METHODS OF INTRODUCING SOFT SKILLS IN THE ELT CONTEXT}

The following section will present methods of including soft skills in the context of foreign language learning and teaching and English language learning courses. The purpose of including soft skills in English language curricula emerged as a result of two requirements. The first requirement came 
from University stakeholders and company representatives, who indicated the need for soft skills implementation in the study curricula at South East European University. The second requirement came on behalf of the University management, including the Faculty Deans, who insisted that the academic programmes for language instruction should move towards the direction of implementing more professionally oriented knowledge and skills which will help students with their professional development and future careers. Of course, elements of soft skills were already existent in the EFL study curricula, but the aim was to emphasize the importance of soft skills, at the same time increasing student awareness even more. Possible ways of embedding soft skills in EFL classroom include the following:

\section{- Task based and problem-solving activities}

These types of activities provide the students with a task/problem which needs to be solved. At the same time they require the students to use the target language. These activities involve meaningful, real-life situations. In addition, they are engaging and interesting for the students. Task-based activities also involve creative and critical thinking and result in team building. At the same time, students contribute ideas and suggestions related to the activity. Problem-solving activities which involve ethical issues and dilemmas are also appropriate, since apart from providing students with an opportunity to use the target language, they also provide a chance to discuss issues related to ethics and morals.

\section{- Group work involving discussions and debates}

The purpose is to embed communication skills as well as interpersonal skills. Students discuss ethical issues related to professional life, particularly specific situations which might emerge in a workplace (for instance conflicts, pressure on one or more employees in the workplace, differences and similarities among the employees, accepting or rejecting authority). Students participate in the group discussion and contribute to the discussion with their ideas and opinions. SWOT activities or strength/weakness/ opportunities/threats analyses activities are also a way to prompt critical thinking skills and problem solving skills.

\section{- Delivering oral and poster presentations}

The purpose is to deliver PowerPoint or poster presentations on specific topics related to students' professional orientation and to evaluate the presentations. Goals and objectives of these activities are to improve speaking skills. At the same time students work on effective and concise communication and aim to communicate their message and/or opinion effectively.

\section{- Role plays and dialogues}

These activities include simulation of meetings, interviews and work-place discussions, as well as workplace situations which involve ethical issues and 
dilemmas, as well as providing feedback to colleagues, subordinates and supervisors. For instance, simulation of a brief staff meeting, job interview or discussion trying to resolve a conflict between two employees require the student to implement their interpersonal skills as well as critical thinking.

\section{- Writing}

Writing appropriate Curricula Vitae, writing appropriate cover letters and e-mails, writing official requests, reports or complaints, using appropriate language and structures are activities which involve writing and require the students to implement their writing skills and communication skills.

Of course, we can conclude that the abovementioned ways of including soft skills are not the only options. However, they can be considered as effective teaching practices which are appealing to the students. Therefore, they can serve as successful ways to introduce soft skills training to undergraduate students. 


\section{REFERENCES}

1. Chamorro-Premuzic, T., Arteche, A., Bremner, A. J., Greven, C., \& Furnham, A. (2010). Soft skills in higher education: importance and improvement ratings as a function of individual differences and academic performance. Educational Psychology, 30(2), 221-241.

2. Nealy, C. (2005). Integrating soft skills through active learning in the management classroom. Journal of College Teaching \& Learning, 2(4), 1-6. Retrieved from file:///C:/Users/e.spirovska/Downloads/1805-7159-1PB\%20(1).pdf

3. Nieragden, G. (2000). The soft skills of Business English. ELT Newsletter. Retrieved from http://www.eltnewsletter.com/back/September2000/art282000.htm

4. Robles, M. M. (2012). Executive perceptions of the top 10 soft skills needed in today's workplace. Business Communication Quarterly, 75(4), 453-465. doi: $10.1177 / 1080569912460400$

5. Schulz, B. (2008). The importance of soft skills: Education beyond academic knowledge. Journal of Language \& Communication, 146-154. Retrieved from

http://ir.polytechnic.edu.na/bitstream/handle/10628/39/The\%20Import ance\%20of\%20Soft\%20\%20Skills-

Education\%20beyond\%20academic\%20knowledge.pdf?sequence=1

6. Shakir,R. (2009). Soft skills at the Malaysian institutes of higher learning. Asia Pacific Education Review, 309-315. Retrieved from http://link.springer.com/article/10.1007/s12564-009-9038-8 


\section{APPENDIX}

\section{PARTICIPANTS' SURVEY}

\section{Please put a tick where appropriate. V}

\begin{tabular}{|c|c|c|c|c|c|}
\hline & Very often & Often & Sometimes & Rarely & Never \\
\hline $\begin{array}{c}\text { Do you believe that you are prepared to work in terms of communicating } \\
\text { with other colleagues and behaving properly at work? }\end{array}$ & 3 & 4 & 12 & 4 & 0 \\
\hline $\begin{array}{l}\text { Do you believe that the relationship between a supervisor and subordinates } \\
\text { in the workplace setting in our society is appropriate? }\end{array}$ & 1 & 3 & 3 & 12 & 4 \\
\hline $\begin{array}{c}\text { Do you believe that your relationship with your colleagues can be } \\
\text { improved? }\end{array}$ & 5 & 5 & 9 & 3 & 1 \\
\hline Have you worked successfully as a member of a team in the past? & 3 & 12 & 5 & 3 & 0 \\
\hline $\begin{array}{c}\text { Have you been in a situation to ask help from colleagues or other members } \\
\text { of your team? }\end{array}$ & 9 & 5 & 5 & 4 & 1 \\
\hline Have you ever had to deal with criticism? & 2 & 5 & 10 & 5 & 1 \\
\hline $\begin{array}{l}\text { 7. Did you have the impression that you had dealt with criticism } \\
\text { successfully? }\end{array}$ & 2 & 5 & 5 & 8 & 3 \\
\hline $\begin{array}{l}8 \text { Have you ever had a situation in which you had to deal with irritated } \\
\text { customers or clients? }\end{array}$ & 4 & 4 & 12 & 3 & 1 \\
\hline $\begin{array}{l}\text { 9. Did you have the impression that you have dealt with irritated clients } \\
\text { successfully? }\end{array}$ & 2 & 4 & 6 & 6 & 4 \\
\hline $\begin{array}{l}\text { Have you developed successful communication with others when you were } \\
\text { new on your current/ most recent job? }\end{array}$ & 4 & 4 & 6 & 6 & 3 \\
\hline $\begin{array}{c}\text { Have you had problems with a supervisor and had to communicate your } \\
\text { unhappy feelings or disagreements? }\end{array}$ & 2 & 6 & 8 & 5 & 2 \\
\hline $\begin{array}{c}\text { Have you ever had to deal with a very tense situation / conflict at work } \\
\text { between yourself and colleagues/ supervisors/clients? }\end{array}$ & 3 & 8 & 10 & 6 & 2 \\
\hline Have you ever had a chance to present an innovative idea or solution? & 2 & 3 & 10 & 6 & 2 \\
\hline $\begin{array}{l}\text { Have you ever had to present/ speak on the phone/listen to a presentation in } \\
\text { English? }\end{array}$ & 3 & 15 & 5 & 0 & 0 \\
\hline $\begin{array}{l}\text { Have you ever had to write e-mails and correspond in a written form in } \\
\text { English language? }\end{array}$ & 4 & 14 & 5 & 0 & 0 \\
\hline $\begin{array}{c}\text { Have you ever had a chance to solve a problem at workplace or other } \\
\text { professional setting? }\end{array}$ & 2 & 8 & 6 & 5 & 2 \\
\hline $\begin{array}{c}\text { Do you think that your University studies could have prepared you better to } \\
\text { deal with unexpected and complicated situations at work? }\end{array}$ & 4 & 8 & 8 & 3 & 0 \\
\hline $\begin{array}{l}\text { Do you think that the skill of understanding and communicating with others } \\
\text { can be learned? }\end{array}$ & 4 & 8 & 8 & 2 & 1 \\
\hline $\begin{array}{l}\text { Have you ever been in a situation to notice an unethical behavior on behalf } \\
\text { of your colleagues? Could you recognize these situations as unethical? }\end{array}$ & 2 & 1 & 8 & 8 & 6 \\
\hline $\begin{array}{c}\text { Were you asked to do something which is not ethical at your workplace? } \\
\text { Could you recognize that this requirement is unethical? }\end{array}$ & 0 & 4 & 8 & 8 & 3 \\
\hline
\end{tabular}

